\title{
DEVELOPMENT AND SENSORY EVALUATION OF NOOTROPIC COOKIES FORTIFIED BARLEY FLOUR TO WHEAT FLOUR WITH MEDHYARASAYANA
}

\section{PUSHPA. H. $\mathrm{K}^{\mathbf{1}}$ \& N. C. VARADACHARYULU ${ }^{2}$}

${ }^{1}$ Research Scholar, Jawaharlal Nehru Technological University, Ananthapur, Andra Pradesh, India

${ }^{2}$ Department of Biochemistry, Sri Krishnadevaraya University, Ananthapur, Andra Pradesh, India

ABSTRACT
Cookies are more widely used staple food for human diet in both developed and developing countries and it is
well accepted by consumers due to their sensory attributes, long shelf life and its ready to eat advantage. The objective of
the present work is to improve the nutritional and the health benefit incorporation of barley flour and Medhya Rasayana
to the wheat based cookies. These cookies improved protein, fat, fiber, ash, $\beta$-glucan and minerals (CA, P, K and Fe)
with low moisture contents. It has nutritional benefit and which have therapeutic value and also health benefits. Sensory
properties of the separation and roundness were not affected significantly; significant difference was seen in taste color
and odor. These cookies are useful for all health of the people and increase cognitive abilities, memory enhancing, and
longevity. These cookies can also be consumed as medicinal supplements for regular consumption and support to
prevent many health problems and promote good health and increase immunity.
KEYWORDS: Medhya Rasayana, Attributes, $\beta$-Glucan, Longevity \& Cognitive Abilities

Received: May 04, 2017; Accepted: May 25, 2017; Published: June 23, 2017; Paper Id.: IJBRJUN20174

\section{INTRODUCTION}

In the present scenario, people are more conscious about health and making food choices based on a food's ability to provide health benefits, such as enhancing body functions or reducing the risk for certain disease. Currently, the healthy foods and drinks market is performing well, in terms of innovation and market satiety; according to A.C. Nielsen data (2007). Bakery products like bread, biscuits and cookies are used as most convenient cereal based products. These are all low cost products and are consumed all over the world, both urban and rural people (Avinash 2014). Cookies have a high content of carbohydrate, fat and low moisture. Wheat flour, sugar, salt is the principal ingredients used in bread, biscuits and cookies making (Gandhi et al., 2001). The bakery products can be used as a vehicle for incorporation of different nutritional rich and nootropic ingredients.

According to Food and Drug Administration (FDA), 3 grams of barley $\beta$-Glucan per day is sufficient dietary intake to achieve a decrease in serum total and low density lipoprotein cholesterol (Sullivan Petal). The importance in the application and the nutritional analysis of the BBG fractions was very successful in illustrating potential health benefits of foods. $\beta$-glucan shows promise in various food systems, including beverages, meat products, and bakery products, (Newman et al (1998) Barley (Hordeumvulgare) is rich in $\beta$ - Glucan and its common Dhanya and traditional staple food in India. It's mainly used as feed for animals and for people used much as medicinal purpose not as a regular diet (Ramesh Chandra Kumawat). Barley considered to be most useful grain, as it is easily digestible compared wheat and other grain (Mohammad). But, still it remains underutilized as human food. Barley malt also can be substituted in to a lot of food stuffs such as biscuits, bread, crackers, cakes, 
desserts, malted soft drink, sauce, soup and Ice cream etc. [TanerAkar] BBG fiber fractions in foods and in human nutrition, particularly where starch is a primary ingredient bread and pasta(C Brennan) overall quality of the breadwas acceptable up to $40 \%$ barley flour fortification, but harder and dark in colour (Basmanand Koksel, 2008) but more acceptable 15-30\% barley flour and 20-30\% barley flour prepared noodles are acceptable characteristics (Cheigh etal., 1976) up to $40 \%$ BF incorporated with wheat flour parota enriched with dietary fiber and b-glucan significantly increase water absorption and dough elasticity. $30 \%$ is more acceptable characteristics compared to 40\% BF (G KoushikaMaiya) and it increases water absorption and dough elasticity, and decreases dough strength, extensibility and parotta-making characteristics of wheat flour. The $30 \% \mathrm{BF}$ parotta showed increased contents of dietary fiber and b-glucan by 2.0 and 10.5 times, $\beta$-Glucan rich parotta on a large scale by the baking industries.(G KoushikaMaiya).

Nootropic herbs are called Medhy Rasayana in Ayurveda (Reena kulakarni et al.). MedhyaRasayana are group of medicinal plants described in Ayurveda (Indian system of medicine) with multi-fold benefits, specifically to improve memory and intellect by Prabhava (specific action). Nootropic in Ayurveda Medha means intellect and/or retention and Rasayana means a therapeutic procedure or preparation that on regular practice will boost nourishment, health, memory, intellect, immunity and hence longevity. ( RenukaKulkarni 2012) Which have multi fold benefits, specifically to improve memory and intellect by their Prabhava (specific action) namely Medhya (Nootropic). The MedhyaRasayan is specifically intellect promoting and bestowing longevity. It also provides immunity against diseases, strength, complexion, voice and digestive capacity. The herbs used include juice of Bacopamonnieri, the powder of Glycerrizaglabra in milk, the juice of roots, stem and flowers of Tinusporacordifolia and paste of Convolvulus pluricaulis (CharakaSamihatha). Specially mentioned with a wide range of applications on different systems. Yet in practice, little more handful drugs used with same aim are mentioned elsewhere in the Ayurveda classical textbooks. They are Aindri (Bacopamonniera), Jyothishmati (Celastruspanniculata), Kushmanda (Benincasahispida), Vacha (Acoruscalamus) and Jatamamsi (Nardostachysjatamamsi). MedhyaRasayana are used either in polyherbal preparations or alone (Renukakulkarni 2012)

\section{MATERIALS AND METHODS}

Collected MedhyaRasayana (Nootropic) herbs [Centella asiatica (Mandukaparni), Bacopamonnieri (JalaBrahmi), Withaniasomnifera (Ashwagandha), Clitoriaternatea (shankapushpi) Tinosporacordifolia (Guduchi) Acoruscalamus (Vacha) Formulated Medhyarasayana according to Ayurveda classical method (Kulkarni Reena et al).

Table 1: Materials for Preparation of Cookies

\begin{tabular}{|c|l|c|}
\hline Sl. No & \multicolumn{1}{|c|}{ Ingredients } & $\begin{array}{c}\text { Amount in } \\
\text { GMs }\end{array}$ \\
\hline 1 & Wheat and Barley premix dough 70:30\%, 60:40\% & 100 \\
\hline 2 & Jagerry (Brown sugar) & 50 \\
\hline 3 & Cow Ghee & 20 \\
\hline 4 & Butter & 20 \\
\hline 5 & Yalachi ( Cad mom) powder & $3 \mathrm{gms}$ \\
\hline 6 & Baking Powder & $1 / 2$ tea spoon \\
\hline 7 & Salt & 1.0 \\
\hline 8 & Date (Paste) & 20 to $40 \mathrm{ml}$ \\
\hline 9 & Water & \\
\hline
\end{tabular}




\section{EXPERIMENTAL PROCEDURE}

\section{Preparation of Dough}

Weigh all the ingredients, mix Brown sugar, Cow Ghee, vanilla, crushed date and baking powder and salt, and also the flour (wheat and barley premix dough) to make smooth dough thoroughly. Each 9 gms weighed premixed ingredients, add one gram of formulating Medhya Rasayana in the addition of water up to consistency mixing.

Preheat the oven $375^{\circ} \mathrm{F}$. Drop dough on microwave baking tray rounded tablespoon full about 2 inches apart onto ungreased cookie sheet $\&$ cook at $100 \%$. It has to be baked in an oven at $90^{\circ} \mathrm{c}$ for $18 \mathrm{mts}$. The proximate analysis with respect to moisture, total ash content, protein, carbohydrate, and fat and fibber value was performed on newly formulated cookies by AOAC method. The level of active components of Medhya Rasayana analysis done by TLC method. Sensory evaluation was carried out by the panel of judges on nine Hedonic scales. The mean value score was given for each parameter like color, flavor, texture, mouth feel and overall acceptability.

Microbial analysis was performed by the standard plate count method (6). $1 \mathrm{ml}$ of an aliquot of the sample was taken in a sterile Petri dish of both dilutions. Tryptone Glucose Beef extract was added in both the dishes, rotated the plates to mix the sample with agar diluents. Incubated the dishes for $48 \mathrm{hrs}$ at $37^{0} \mathrm{C}$. Counted the colonies and calculated the Total Viable Count (TVC) per gram.

\section{RESULTS AND DISCUSSIONS}

Table 2: Chemical Parameters of the Newly Formulated Cookies

\begin{tabular}{|l|c|c|c|c|}
\hline \multicolumn{1}{|c|}{$\%$ Parameter } & Fresh & $\mathbf{1}^{\text {st }}$ Week & $\mathbf{2}^{\text {nd }}$ Week & $\mathbf{3}^{\text {rd }}$ Week \\
\hline Moisture & 0.76 & 1.14 & 1.58 & 1.96 \\
\hline Total Ash & 1.03 & 1.07 & 1.05 & 2.10 \\
\hline Acid Insoluble Ash & 0.07 & 0.10 & 1.19 & 1.53 \\
\hline Carbohydrate & 61.39 & - & - & - \\
\hline Protein & 7.13 & - & - & - \\
\hline Fat & 25.73 & - & - & - \\
\hline Dietary Fiber & 0.79 & - & - & -- \\
\hline
\end{tabular}

From Table 2 Chemical parameter are studied for Fresh, First, Second and third week. It is observed that moisture, ash and acid values are increased as the days increased. The quality of the cookies is decreased and life span of the cookies also is reduced.

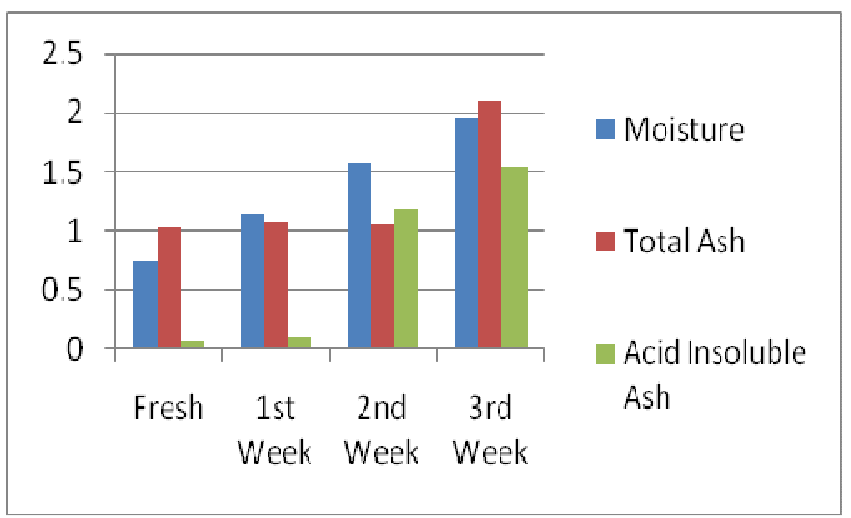

Figure 1: Shelf Life of Cookies 
Table 3: Sensory Analysis of Barley Flour Fortified to Wheat Flour with Medhya Rasayana Churna Prepared Cookies

\begin{tabular}{|l|c|c|c|c|c|c|c|c|}
\hline \multicolumn{1}{|c|}{ Characteristics } & \multicolumn{2}{c|}{ Fresh } & \multicolumn{2}{c|}{$\mathbf{1}^{\text {st }}$ Week } & \multicolumn{2}{c|}{$\mathbf{2}^{\text {nd }}$ Week } & \multicolumn{2}{c|}{$3^{\text {rd }}$ Week } \\
\hline Wheat : Barley in \% & $70: 30$ & $60: 40$ & $70: 30$ & $60: 40$ & $70: 30$ & $60: 40$ & $70: 30$ & $60: 40$ \\
\hline Appearance (15) & 13 & 13 & 12.0 & 12 & 11.3 & 11.2 & 8.9 & 8.9 \\
\hline Colour(15) & 9.9 & 9.9 & 9.60 & 9.5 & 9.4 & 9.4 & 8.1 & 8.0 \\
\hline Crispiness(15) & 10 & 9.7 & 9.1 & 9.0 & 7.9 & 7.5 & 5.1 & 4.9 \\
\hline Flavor(15) & 12 & 12 & 10.0 & 10.0 & 6.8 & 6.8 & 5.1 & 5.1 \\
\hline Taste(15) & 10 & 10 & 8.0 & 8.0 & 5.0 & 5.0 & 5.0 & 5.3 \\
\hline Texture(15) & 9.1 & 9.1 & 9.3 & 9.0 & 5.9 & 5.9 & 5.3 & 5.5 \\
\hline Overall Acceptance (10) & 7.3 & 7.3 & 5.8 & 5.8 & 5.1 & 5.0 & 5.0 & 5.0 \\
\hline \multicolumn{1}{|c|}{ Total (100) } & $\mathbf{7 3 . 3}$ & $\mathbf{7 1}$ & $\mathbf{6 4 . 1}$ & $\mathbf{6 3 . 3}$ & $\mathbf{5 1 . 4}$ & $\mathbf{5 0 . 8}$ & $\mathbf{4 2 . 5}$ & $\mathbf{4 2 . 7}$ \\
\hline
\end{tabular}

From Table 3 There is no much significant difference from barley fortification $30 \%$ and $40 \%$ shown in sensory analysis. When compared between first and third weeks, it is found that the overall quality of the cookies glot decreased.

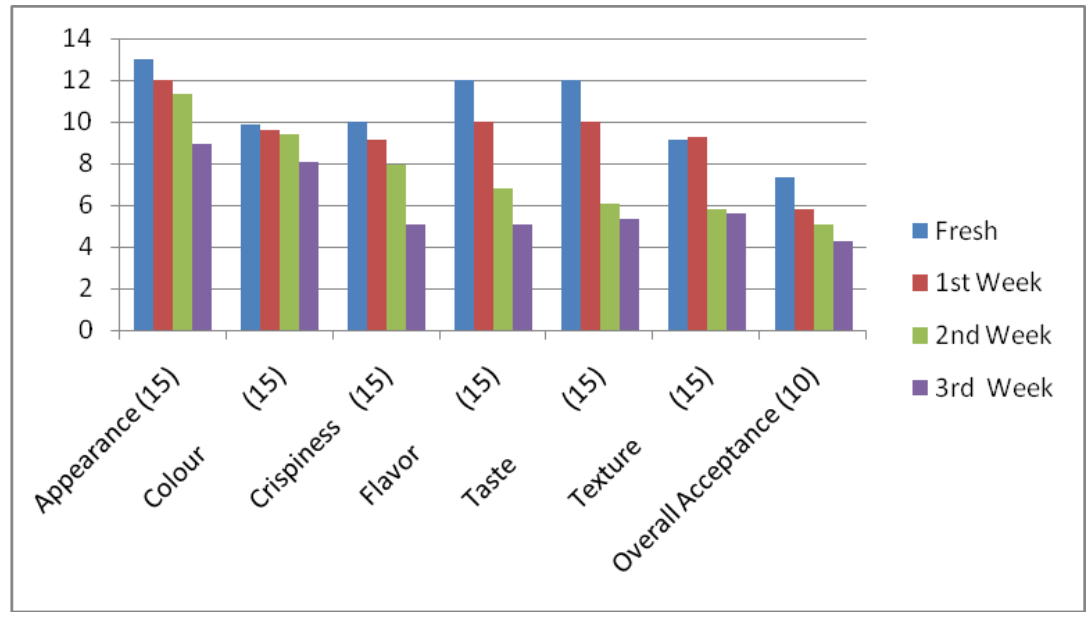

Figure 2: Sensory Analysis Formulated Cookies

\section{CONCLUSIONS}

Sensory properties of the separation and roundness were not affected significantly; there was no significant difference seen in taste color and odor 30\% barley fortification. $40 \%$ fortification barley cookies had good texture and crispiness. These cookies are rich in carbohydrate, protein and fiber. It has high nutritive value and it holds good for all age groups from children to age hold people. Studies reveal that herbs retain active component, even after baking. These cookies are useful for all healthy people to increase cognitive abilities, enhanced memory, longevity and also to prevent diseases such as fatness, heart and blood vessel diseases. These cookies can also be consumed as medicinal supplements for regular consumption due to its ready to eat advantages. It supports to prevent many health problems and promote good health and increase immunity. 


\section{REFERENCES}

1. A.C Nielsen (2008). What's Hot Around the Globe: Food \& Beverage Macro-trends, evoluzionedeglistili DI vita, comportamentid'acquistodeiprodottialimentarinelmondo.

2. Avinash Singh Patel, Arun Kumar Pandey, Fortification of Limoniaacidissima Linn Fruit Powder to Develop the Phynolic Enriched Herbal biscuits, Journal Bio resource Engineering Technology, 2014.

3. Basmanand Ko" kse et al., Barley for food: Characteristics, improvement, and renewed interest, Journal of Cereal Science 48 (2): 233-242 - September 2008

4. C Brennan, Effects of $\beta$-glucan fractions from barley on structure, texture, sensory characteristics and nutritional value of processed cereal foods, HGCA project No. 2730, d Report No. 346 August 2004.

5. CharakSamhita, PV Sharma, 4th Edition, 1998 ChaukhambhaOrientalia Varanasi, Section6 Chikitsasthanam, Chapter 1, Qtr 3, pp 23, Shloka 30-31.

6. Cheigh, H, S, Ryu, C, H, Kwon, T.W, Preparation and evaluation of dried noodles using barley-wheat and barley-soybean flours. Korean Journal of Food Science and Technology 8, 236-241 (1976)

7. Frazier WC and Westoff DC (1195), Food Microbiology, Tata Hill Publishing Co. Ltd P.3 -4,

8. G KoushikaMaiya, BG Shwetha and D Indrani, Effect of barley flour on rheological characteristics of dough, organoleptic, nutritional and storage characteristics of south Indian parade, Science and Technology International 21 (1) 24-32. 2013.

9. Kulkarni Reena, Kumar Abhimanyu, Koppala Narayana Sunil Kumar, Formulation and standardization of Medhya Rasayana e A novel Ayurvedic compound nootropic drug Pharmacognosy Journal 5 (2013) $72-76$

10. Newman, R.K., Ore, K.C., Abott, J., Newman, C.W. 1998. Fiber enrichment of baked products with a barley milling fraction. Cereal Foods World. 43(1):23-25

11. ReenaKulkarni, Kumar Abimanyu et al., Formulation and standardization of MedhyaRasayana A novel Ayurvedic compound nootropic drug, Pharmacognosy Journal 5 (2): 72-76 · March 2013

12. Sullivan, $P$ et al., The increasing use of Barley and barley byproducts in the production of healthier baked goods, Trends in Food Science and Technology 2013;29:124-134. 
